\title{
IBM KKG SD GUGUS DIPAYUDA BANJARNEGARA
}

\author{
Wadiyo, Slamet Haryono
}

FBS Universitas Negeri Semarang

Email:wadiyo@mail.unnes.ac.id

\begin{abstract}
KKG SD cluster Dipayuda is one of the clusters in Banjarnegara. SD $K K G$ for each cluster in Kabupaten Banjarnegara are all active in performing their tasks, including the Dipayuda cluster. Many things are done in an effort to improve the professionalism of teachers, including the desire to be able to create songs that are themed education. The problem that arises in this devotion is "how can the Dipayuda cluster teachers produce the songwriting that fits the theme of learning?". The method of activity in the devotion to the community is run by means of classical song-making training. The result of the dedication to the community showed that the intimacy of the participants of the devotion as the Diayuda clan to be able to create songs according to the learning theme is very high seen from their efforts in the training process. Even so the participants still need to study hard so that the work of the creativity can be easily accepted by the students with a single sung stimulate students to imitate.
\end{abstract}

Keywords: Songs; Learning Theme; Creation; Teaching material

\begin{abstract}
Abstrak. KKG SD gugus Dipayuda merupakan salah gugus yang ada di Banjarnegara. KKG SD untuk setiap gugus di Kabupaten Banjarnegara semuanya aktif menjalankan tugas kegugusannya, termasuk gugus Dipayuda. Banyak hal yang dilakukakan dalam upaya meningkatkan keprofesionalan guru itu termasuk keinginan untuk dapat menciptakan lagu-lagu yang bertema pendidikan. Permasalahan yang muncul dalam pengabdian ini adalah "bagaimana para guru gugus Dipayuda dapat membuahkan karya cipta lagu yang sesuai dengan tema pembelajaran?". Metode kegiatan pada pengabdian kepada masyarakat dijalankan dengan cara pelatihan pembuatan lagu secara klasikal. Hasil pengabdian kepada masyarakat menujukkan, keantosiasan para peserta pengabdian sebagai insan gugus Diayuda untuk dapat mencipta lagu sesuai tema pembelajaran sangat tinggi terlihat dari usaha-usaha mereka dalam proses pelatihan. Sekalipun demikian para peserta masih perlu belajar keras agar karya ciptanya dapat mudah diterima oleh para murid dengan sekali dinyanyikan merangsang siswa untuk menirukan.
\end{abstract}

Kata kunci: Lagu; Tema Pembelajaran, Penciptaan, Materi ajar

\section{PENDAHULUAN}

Kabupaten Banjarnegaran terdiri dari 20 kecamatan. Yang setiap kecamatan memiliki gugus kelompok kerja guru (KKG) untuk Sekolah Dasar. Melalui observasi awal, wilayah kecamatan Banjarnegara setidaknya memiliki 43
Sekolah Dasar. Salah satunya adalah SDN 1 Krandegan dengan alamat sekolah di Jalan Dipayuda 23 Banjarnegara. Di SDN 1 Krandegan ini lah digunakan sebagai pusat kelompok kerja guru Sekolah Dasar (KKG) dalam bentuk gugus yang diberi nama KKG Gugus Dipayuda Banjarnegara. 
KKG SD untuk setiap gugus di Kabupaten Banjarnegara semuanya aktif menjalankan tugas kegugusannya, termasuk gugus Dipayuda. KKG dilaksanakan 1 bulan 4 kali setiap hari Sabtu. Materi kegiatan berkait dengan peningkatan profesionalisme guru. Banyak hal yang dilakukakan dalam upaya meningkatkan keprofesionalan guru itu, yang tidak kalah pentingnya adalah peningkatan kualitas pembelajaran. Kualitas pembelajaran pada seluruh mata ajar semua dianggap prioritas, tidak ada yang dianggap tidak prioritas. Intinya, semua dianggap penting yang tidak dibeda-bedakan.

Seluruh mata ajar digunakan untuk membantu anak didik agar menjadi generasi penerus yang berkualitas. Pendidikan dijalankan untuk membangun generasi penerus yang mumpuni, yang ke depan setiap insan anak didik harus dapat mengatasi tuntutan kebutuhan kehidupannya di masyarakat. Misi pendidikan yang dijalankan secara umum adalah pendidikan manusia seutuhnya. Lahir, batin, jasmani, rokhani, mental, dan spiritual. Semua dijalankan secara berkeseimbangan.

Salah satu kesadaran bagi para guru Sekolah Dasar di Banjarnegara adalah perlunya mendidik anak dengan musik. Musik dianggap memiliki peran penting dalam membantu kecerdasan anak, baik SQ, IQ, maupun EQ. Berkait dengan SQ, semua bisa merasakan bahwa, dengan mendengarkan musik religius misalnya, kepekaan spiritual bisa meningkat. Terhadap IQ, sebuah riset terhadap beberapa siswa murid Sekolah Dasar (lihat Simpony Otak karya Stephanie Merritt, 1996) menunjukkan, mereka yang menduduki peringkat satu sampai lima di kelas adalah anak-anak yang semuanya akrap dengan musik. Mengenai EQ, tak perlu diragukan lagi, telah sering kita mendengar adanya pereda stress dengan musik (lihat juga Rene Van de Carr dan Marc Lehrer, 2004; Djohan, 2003).

Berkait dengan pentingnya musik untuk anak-anak Sekolah Dasar yang disadari oleh para guru Sekolah Dasar di Kabupaten Banjarnegara, di awal tahun 2017 ini, kami tim pengabdian telah diminta oleh guru-guru Kabupaten Banjarnegara di Banjarnegara untuk memberikan sesuatu pandangan terhadap pentingnya musik bagi anak-anak Sekolah Dasar. Para guru berkumpul disebuah tempat bersama dengan para murid dan kami tim pengabdian yang ketika itu belum ada niatan untuk melakukan pengabdian masyarakat diminta untuk berbicara mengenai musik dan kegunaannya untuk anak-anak. Kami menjelaskan kepada para guru dan siswa ikut mendengarkan.

Pada kesempatan itu, para guru kita ajak bernyanyi, demikian pula dengan para siswa dengan semuanya menggunakan lagu-lagu baru ciptaan tim pengabdi yang belum dikenal sama sekali baik oleh guru maupun para murid. Lagu-lagu itu benarbenar baru yang belum pernah diperkenalkan pada mereka selain sedikit oleh tim pengabdian yang telah pernah memperkenalkannya pada salah satu kelompok guru Sekolah Dasar di Semarang. Semua guru senang, semua murid juga senang. Semua guru bisa menyanyikan dengan baik, para murid pun juga dapat menyanyikan dengan merdu. Semua guru tahu dan atau mengerti pesan lagu yang kita nyanyikan bersama, demikian pula para murid.

Hasil pertemuan dengan para guru Sekolah Dasar Banjarnegara itu adalah makin disadarinya pentingnya musik untuk anak-anak Sekolah Dasar untuk berbagai kepentingan dalam konteks membantu kecerdasan para siswa, baik itu kecerdasan logika, kecerdasan rasa, dan juga kecerdasan spiritual. Apa yang dirasakan paling mudah dilakukan adalah 
bernyanyi. Semua menyadari, melalui nyanyian, segala pesan yang ada pada lagu yang dinyanyikan dan atau didengar dapat ditangkap pesannya dengan indah. Selain nuansa estetik sebagai pendidikan estetik didapat oleh para siswa, mereka juga dapat menangkap pesan lagu itu dengan santai.

Di sini dapat digunakan memasukkan materi ajar lewat lagu. Dapat digunakan memasukkan pesan pendidikan lewat lagu. Ini yang disadari bersama dalam pertemuan itu karena kita bersama dalam pertemuan itu telah mempraktekkan semua. Permasalahan utama akhirnya muncul mengenai sulitnya mendapatkan lagu-lagu yang cocok untuk usia anak Sekolah Dasar, lagu-lagu yang bertema pendidikan dan atau lagu-lagu yang berisi tentang tuntunan pengetahuan dan atau tuntunan perilaku yang cocok untuk usia anak-anak Sekolah Dasar. Yang paling tahu dan atau mengerti mengenai pesan apa yang akan disampaikan oleh guru untuk anak didiknya adalah para guru itu sendiri. Untuk itulah, mau tidak mau para guru harus membuat lagu sesuai dengan pesan lagu yang diinginkan.

Kendalanya akhirnya muncul, tidak mudah untuk membuat lagu. Para guru perlu mendapat penyuluhan tentang bagaimana membuat lagu untuk memasukkan materi ajar kepada anak didik lewat lagu. Ini sebetulnya yang akhirnya diminta oleh para guru Sekolah Dasar Banjarnegara, yakni tentang pengetahuan mencipta lagu. Hanya dalam kesempatan pengabdian kepada masyarakat inilah permasalahan itu tampaknya dapat dijalankan. Jumlah guru sekabupaten Banjarnegara sangatlah banyak. Tidak mungkin dalam waktu bersamaan tim pengabdian dapat melakukan itu. Permintaan dari para guru Sekolah Dasar Banjarnegara akhirnya minta supaya KKG SD Gugus Dipayuda Banjarnegara diadakan pelayanan pengabdian kepada masyarakat tentang penciptaan lagu terlebih dahulu. Harapannya, pengetahuan dari KKG Gugus Dipayuda dalam hal penciptaan lagu itu nanti dapat ditularkan ke gugusgugus yang lain.

\section{Permasalahan}

Berdasar latar belakang masalah yang telah dikemukakan secara panjang lebar, dapat dirumuskan permasalahan singkat "Bagaimana penciptaan lagu anakanak yang memuat pesan pendidikan dapat dilakukan oleh para guru Sekolah Dasar"

\section{Tujuan Kegiatan}

Berdasar analisis situasi dengan pemunculan masalah yang diangkat dalam pengabdian kepada masyarakat ini, dapat disampaikan tujuan pengabdian, yakni untuk "Memberikan dasar-dasar cara mencipta lagu anak-anak yang bermuatan pesan pendidikan untuk para guru khususnya Kelompok Kerja Guru Sekolah Dasar Gugus Dipayuda Banjarnegara”.

\section{METODE PELAKSANAAN}

Ada beberapa metode atau cara sebagai solusi untuk mendidik anak agar suatu proses pembelajaran dalam konteks ini anak Sekolah Dasar sampai pada tujuan yang diinginkan. Bernyanyi merupakan salah satu cara dan atau kegiatan dalam pembelajaran yang diharapkan mampu memberikan sumbangan terhadap pencapaian pendidikan. Melalui lagu, anak akan menghayati arti hormat kepada orang tua, sayang terhadap sesamanya, mencintai alam, mencintai tanah air, kagum kebesaran Tuhan, dan lain sebagainya yang kesemuanya itu akan menumbuhkan nilai yang membantu sikap perilaku memapak kedewasaan, disamping menumbuhkan minat dan bakat musikalnya (Mahmud, 1981).

Mengingat begitu pentingnya arti bernyanyi bagi anak didik, maka 
seyogyanya para guru Sekolah Dasar perlu diberi bekal yang cukup memadai mengenai keterampilan bernyanyi menuju kepenciptaan lagu menggunakan media senandung. Dengan bernyanyi, pesanpesan pendidikan melalui lagu akan dapat diserap oleh siswa dengan rasa senang dan mengesan. Dengan nyanyian, siswa dapat belajar apapun melalui arti dari lirik lagu yang ia tangkap dan ia rasakan. Dengan demikian, tampaknya menjadi sesuatu keharusan yang tidak perlu ditawar-tawar, bahwa seorang guru seyogyanya mampu bernyanyi dan mencipta lagu untuk anak didiknya.

Penciptaan lagu, mestinya dapat dilakukan oleh para guru karena lagu itu hanya kata-kata diungkapkan lewat nada dan irama. Kendala utama penciptaan lagu ini karena guru tidak mempunyai bekal yang cukup dalam hal mencipta lagu, baik itu lagu sebagai karya seni ataupun sekedar lagu sebagai media pencapaian tujuan pembelajaran (Hasil penelitian Utomo Dimuat dalam Jurnal Seni Sendratasik, 2005; Laporan Hasil Penelitian Wadiyo dan KawanKawan1998，2009，2010，2011，2012, 2013, 2015, 2016 ). Berdasar kondisi seperti itu lah, maka penting dilakukan pengabdian masyarakat kepada para guru Sekolah Dasar agar para guru dapat mempunyai bekal pengetahuan dan pengalaman yang cukup dalam hal bernyanyi yang akhirnya mampu mencipta lagu untuk menyampaikan segala pesan pendidikan yang diinginkan untuk anak didiknya.

Pendekatan yang akan diterapkan untuk mengatasi permasalahan mitra ini adalah dengan cara melatih para guru yang berhubungan dengan membaca notasi musik, begitu pula akan dilaksanakan pelatihan bernyanyi menggunakan lagulagu yang bertema pendidikan sesuai yang dibutuhkan guru dalam pelaksanaan pembelajaran di kelas. Setelah itu barulah dilatihkan penciptaan lagu. Rencana pemecahan masalah akan digambarkan secara sederhana berikut ini.

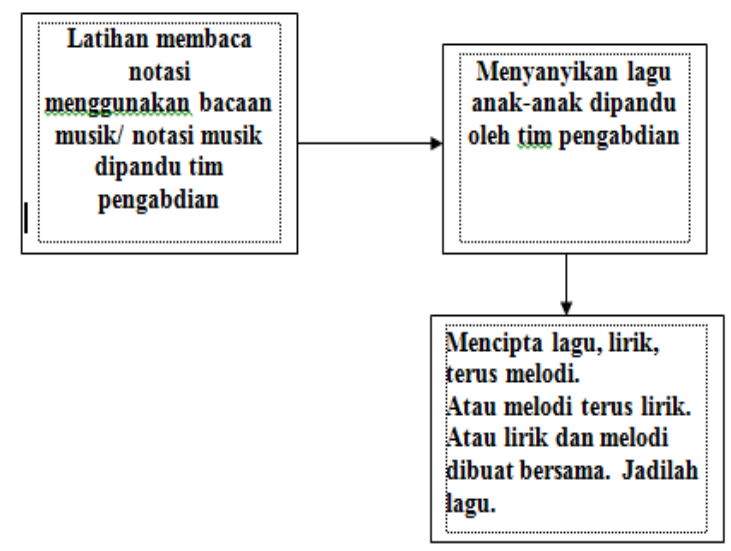

\section{HASIL DAN PEMBAHASAN}

Berdasar rangkaian latar belakang masalah dan metode dalam kaitannya dengan pelaksanaan pengabdian kepada masyarakat, berikut disampaikan hasil pengabdian beserta pembahasannya, yaitu mengenai hasil pengabdian kepada masyarakat yang berhubungan dengan bagaimana penciptaan lagu anak-anak yang memuat pesan pendidikan dapat dilakukan oleh para guru Sekolah Dasar.

\section{Proses Penjelasan Materi}

Sebagaimana telah dikemukakan pada sesi metode pelaksanaan pengabdian kepada masyarakat, dikemukakan bahwa ada beberapa metode atau cara sebagai solusi untuk mendidik anak agar suatu proses pembelajaran dalam konteks ini anak Sekolah Dasar sampai pada tujuan yang diinginkan. Bernyanyi merupakan salah satu cara dan atau kegiatan dalam pembelajaran yang diharapkan mampu memberikan sumbangan terhadap pencapaian pendidikan. Melalui lagu, anak akan menghayati arti hormat kepada orang tua, sayang terhadap sesamanya, mencintai alam, mencintai tanah air, kagum kebesaran Tuhan, dan lain sebagainya 
yang kesemuanya itu akan menumbuhkan nilai yang membantu sikap perilaku memapak kedewasaan, disamping menumbuhkan minat dan bakat musikalnya.

Disampaikan dalam proses pengabdian kepada para guru bahwa, mengingat begitu pentingnya arti bernyanyi bagi anak didik, maka seyogyanya para guru Sekolah Dasar perlu diberi bekal yang cukup memadai mengenai keterampilan bernyanyi menuju kepenciptaan lagu menggunakan media senandung. Dengan bernyanyi, pesanpesan pendidikan melalui lagu akan dapat diserap oleh siswa dengan rasa senang dan mengesan. Dengan nyanyian, siswa dapat belajar apapun melalui arti dari lirik lagu yang ia tangkap dan ia rasakan. Dengan demikian, tampaknya menjadi sesuatu keharusan yang tidak perlu ditawar-tawar, bahwa seorang guru seyogyanya mampu bernyanyi dan mencipta lagu untuk anak didiknya. Bernyanyi dan mencipta lagu untuk anak didiknya.

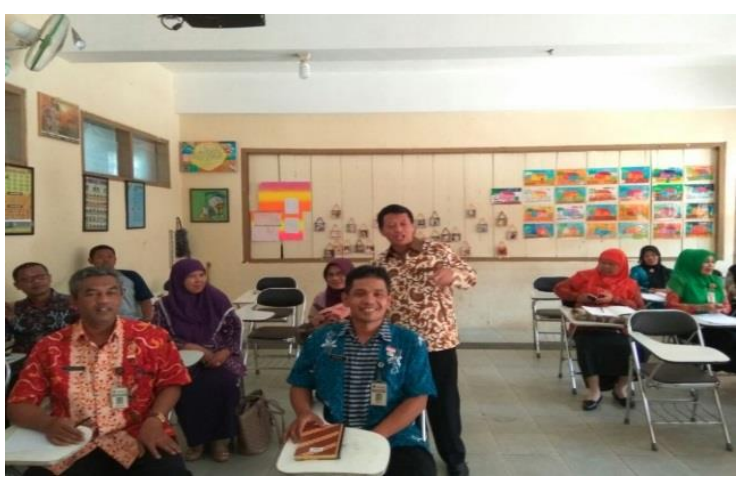

Gambar 1. Tim Pengabdi Menjelaskan tentang Pentingnya Lagu untuk Anak Didik

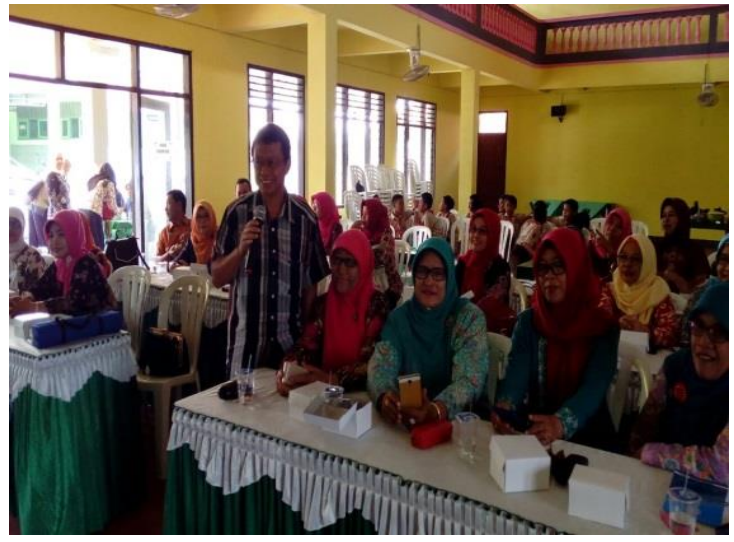

Gambar 2.Tim Pengabdian sedang Minta Contoh Lagu Tuk memasukkan Materi Ajar

\section{Proses Pelatihan Penciptaan Lagu}

Penciptaan lagu, mestinya dapat dilakukan oleh para guru karena lagu itu hanya kata-kata yang diungkapkan lewat nada dan irama. Kendala utama penciptaan lagu ini karena guru tidak mempunyai bekal yang cukup dalam hal mencipta lagu, baik itu lagu sebagai karya seni ataupun sekedar lagu sebagai media pencapaian tujuan pembelajaran. Berdasar kondisi seperti itu lah, maka tim pengabdian melakukan kegiatan ini, yang dirasakan bersama bahwa ini penting dilakukan utamanya pengabdian masyarakat kepada para guru Sekolah Dasar agar para guru dapat mempunyai bekal pengetahuan dan pengalaman yang cukup dalam hal bernyanyi yang akhirnya mampu mencipta lagu untuk menyampaikan segala pesan pendidikan yang diinginkan untuk anak didiknya. Berikut diberikan contoh elemen lagu anak anak yang populer dan atau sudah dikenal oleh para guru sejak para guru masih duduk dibangku sekolah Taman Kanak-kanak. 


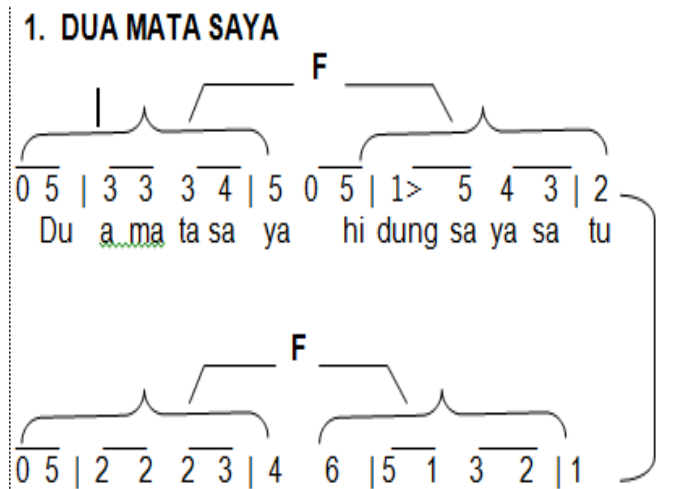

Du a ka ki sa ya pa kai spa tu ba ru

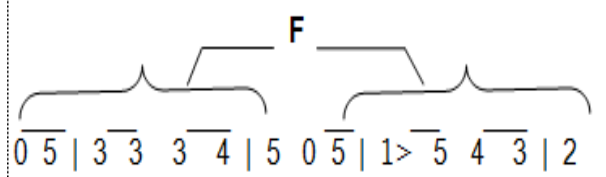

Du a tlinga sa ya yang ki ri danka nan

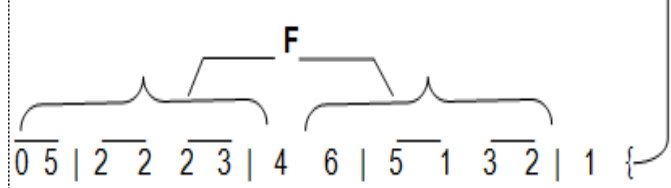

Sa tu mulut sa ya ti dakbrenti ma kan

\section{LIHAT KEBUNKU}

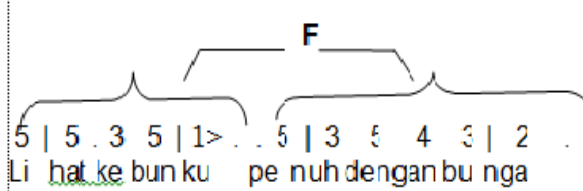

Li hat ke bun ku pe nuh denganbu nga

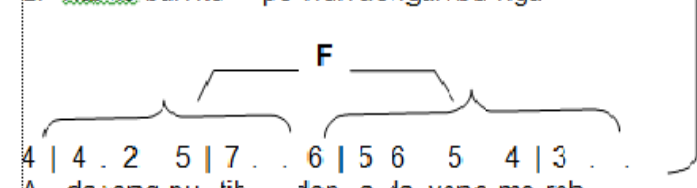

A da yang pu tih dan a da yang me rah

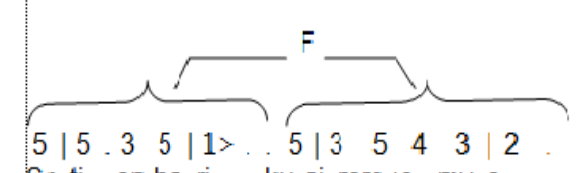

Seti apha ri ku si ramse mu a

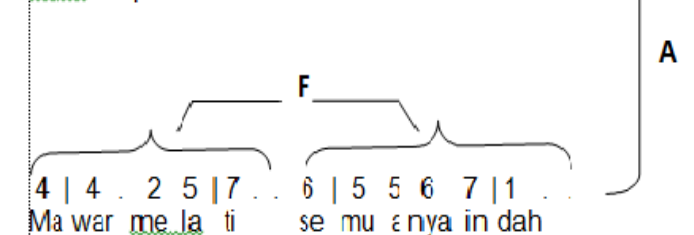

\section{BANGUN PAGI}

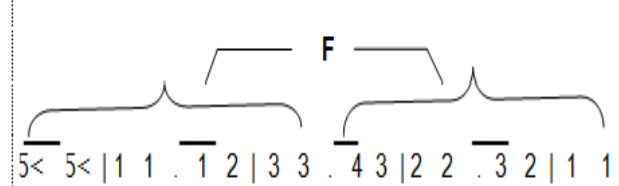

A

Satu du a, ti ga empat Li maenam tu juhdlapan

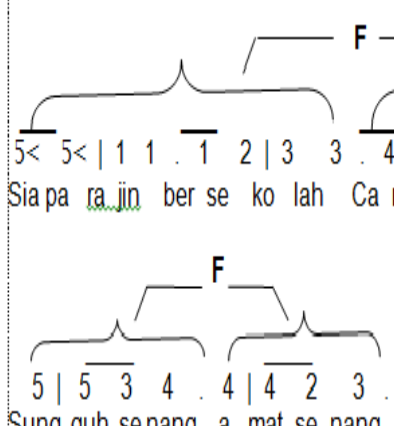

sung guh senang, a mat se nang

A

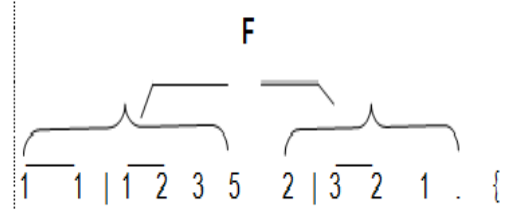

Ba ngun pa gi pa gi sungguh se nang

\section{BURUNG HANTU}

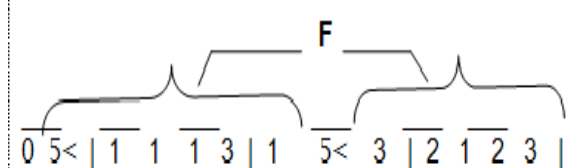

Ma ta ha ri ter be namha rimulai ma lam

A

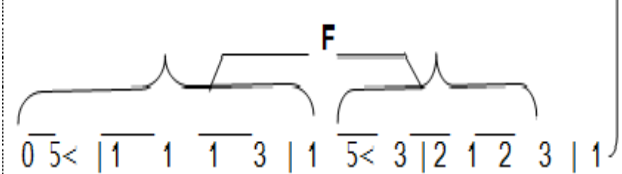

Ter de ngar burunghantu su a ra nyamer du

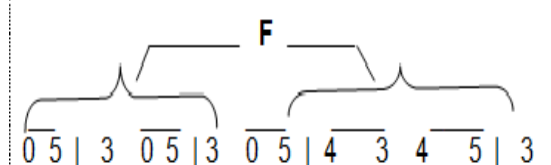

Kuk kuk.., Kukkuk.., Kukkuk..Kuk kuk,.Kukkuk.

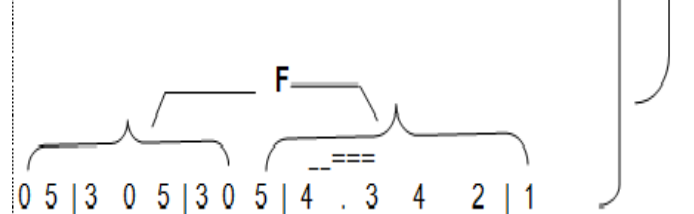

Kukkuk.., Kukkuk, Kukkuk..,Kuk kuk.' Kuk kuk.., 
Sebagaimana dikemukakan pada sesi metode penelitian, pendekatan yang diterapkan untuk mengatasi permasalahan mitra ini adalah dengan cara melatih para guru yang berhubungan dengan membaca notasi musik, begitu pula dilaksanakan pelatihan bernyanyi menggunakan lagulagu yang bertema pendidikan sesuai yang dibutuhkan guru dalam pelaksanaan pembelajaran di kelas. Latihan membaca notasi dan menyanyikan diberikan menggunakan lagu-lagu sebagaimana yang telah dikemukakan itu.

\section{Penciptaan Lagu}

Apa yang dilakukan oleh para guru adalah memilih menuangkan materi terlebih dahulu, namun juga ada yang langsung membuat semacam puisi. Maksud para guru adalah yang penting menuangkan isi materi terlebih dahulu apapun wujudnya. Berikut tuangan materi dan atau isi materi yang dituangkan dalam tulisan yang maksud para guru digunakan sebagai bahan membuat lagu.

\section{Konduktor}

Konduktor apa maksudnya

Penghantar panas yang baik

Isolator apa maksudnya

Tidak menghantar panas

Wajan, panci, dan logam

Itu contoh konduktor

Kayu, plastik, dan kain

Itu isolator

Berikut perwujudannya dalam lagu yang dibuat oleh salah satu guru yang masih perlu disempurnakan.

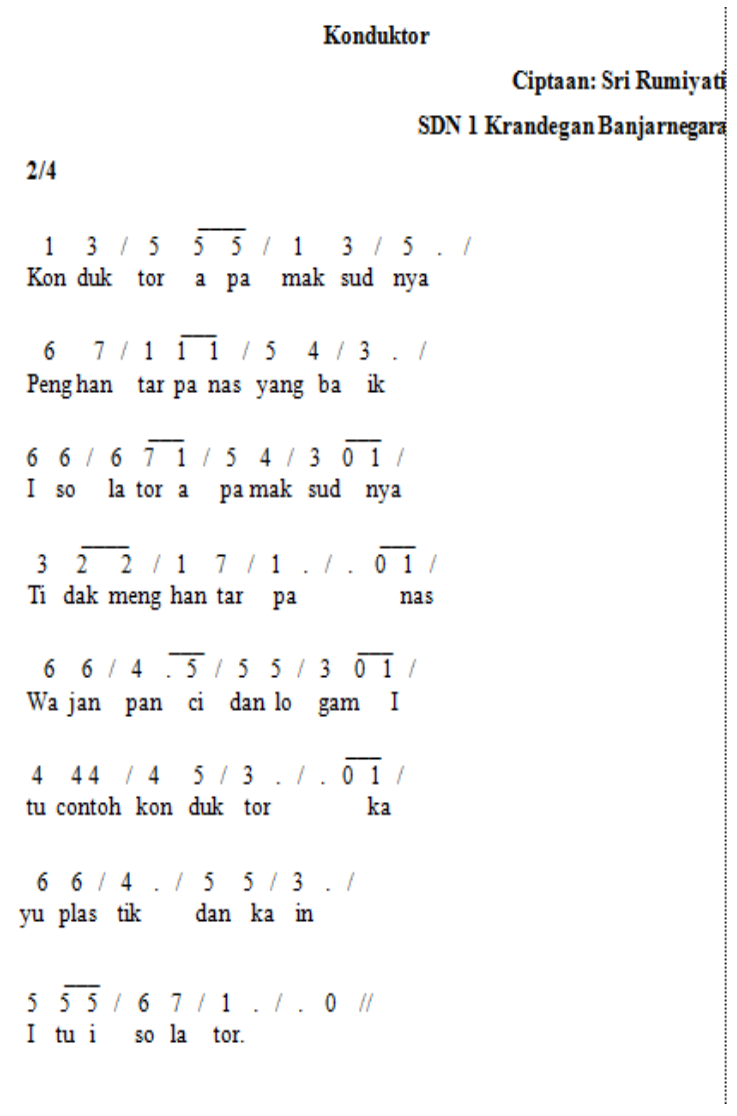

\section{Perpindahan Panas}

Ada tiga macam perpindahan panas

Konduksi, konveksi, dan radiasi

Sinar matahari sampai ke bumi

Itulah contohnya radiasi

Benda padat ujungnya terasa panas

Itulah contohnya konduksi. 


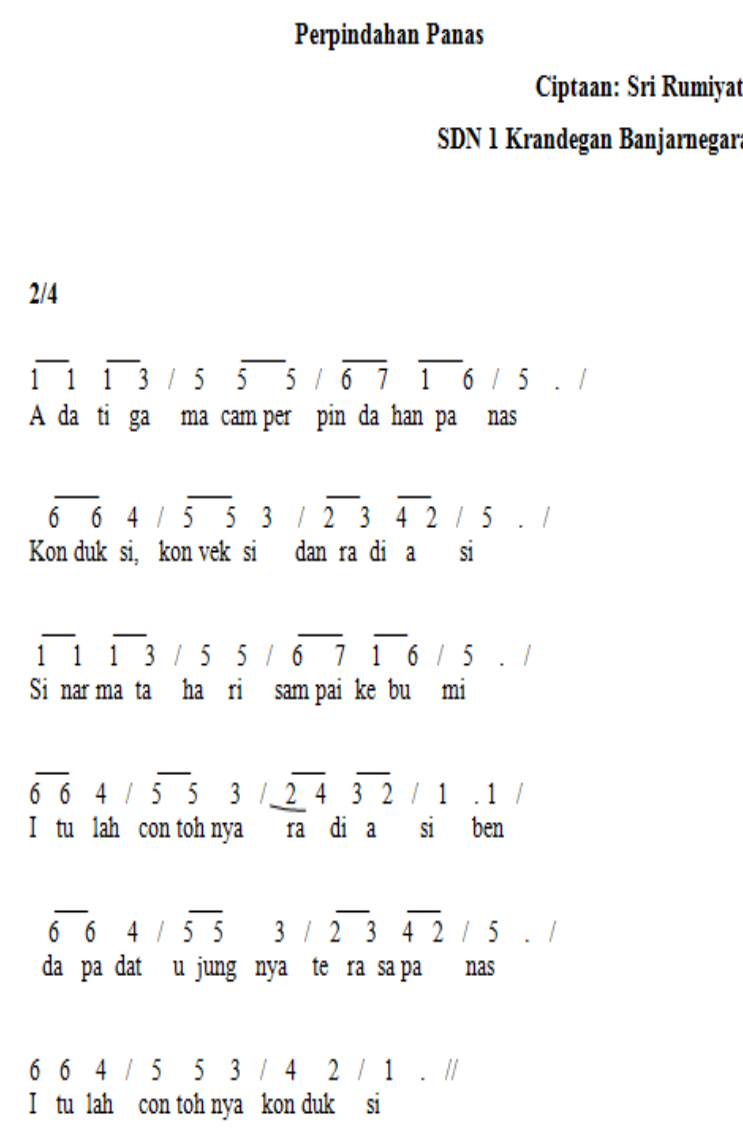

Selanjutnya tim pengabdian menunjukkan tema-tema pembelajaran dari SD kelas 1 sampai dengan SD kelas Vl.

\section{Kelas 1}

Tema 1 : Diriku

Tema 2 : Kegemaranku

Tema 3 : Kegiatanku

Tema 4 : Keluargaku

Tema 5 : Pengalamanku

Tema 6 : Lingkungan Bersih, Sehat, dan Asri

Tema 7 : Benda, Hewan, dan Tanaman di Sekitarku

Tema 8 : Peristiwa Alam

\subsection{Kelas ll}

Tema 1 : Hidup Rukun

Tema 2 : Bermain di Lingkunganku

Tema 3 : Tugasku Sehari-hari

Tema 4 : Hidup Bersih dan Sehat

Tema 5 : Aku dan Sekolahku

Tema 6 : Air, Bumi, dan Matahari
Tema 7 : Merawat Hewan dan

Tumbuhan

Tema 8 : Keselamatan di Rumah dan di Perjalanan

1.2 Kelas III

Tema 1 : Pertumbuhan dan

Perkembangan Makhluk Hidup

Tema 2 : Menyayangi Tumbuhan dan

Hewan Sekitar

Tema 3 : Benda di Sekitarku

Tema 4 : Hak dan kwajibanku

Tema 5 : Perubahan Cuaca

Tema 6 : Energi dan perubahannya

Tema 7 : Perkembangan dan teknologi

Tema 8 : Praja Muda Karana

\subsection{Kelas IV}

Tema 1 : Indahnya kebersamaan

Tema 2 : Selalu Berhemat Energi

Tema 3 : Peduli Terhadap Makhluk

Hidup

Tema 4 : Berbagai Pekerjaan

Tema 5 : Pahlawanku

Tema 6 : Indahnya Negeriku

Tema 7 : Cita-citaku

Tema 8 : Tempat Tinggalku

Tema 9 : Makanan Sehat dan Bergizi

\subsection{Kelas V}

Tema 1 : Organ gerak Hewan dan

Manusia

Tema 2 : Udara Bersih

Tema 3 : Makanan Sehat

Tema 4 : Organ Peredaran Darah

Tema 5 : Ekosistem

Tema 6 : Kalor dan Perpindahannya

Tema 7 : Benda-benda di Sekitar

Tema 8 : Peristiwa dalam Kehidupan

Tema 9 : Lingkungan Sahabat Kita

\subsection{Kelas VI}

Tema 1 : Selamatkan Makhluk Hidup

Tema 2 : Persatuan dalam Perbedaan

Tema 3 : Tokoh dan Penemuan

Tema 4 : Globalisasi

Tema 5 : Wirausaha

Tema 6 : Menuju Masyarakat Sehat

Tema 7 : Kepemimpinan

Tema 8 : Bumiku

Tema 9 : Menjelajah Angkasa Luar 
Seluruh peserta pengabdian oleh tim pengabdian diminta untuk mempelajari tema-tema itu. Para guru pun menjelaskan bahwa, tema-tema itu materinya harus dicari di buku-buku pembelajaran kelas karena pihak dinas pendidikan belum memberikan materi ajar dalam bentuk buku berdasar tema pembelajaran yang telah dibuat kelas satu sampai kelas enam itu. Selama ini para guru ketika mengajar dengan harus menggunakan tema-tema pembelajaran yang telah dituangkan dalam kurikulum mengikuti kurikulum 13 edisi revisi 2016, masih sekedar menjalankan dengan perasaan belum puas. Berdasar kondisi ini, tim pengabdian menunjukkan contoh dua lagu tentang Lingkungan Sahabat Kita untuk kelas V yang dibuat oleh tim pengabdian

\section{HUTANKU}
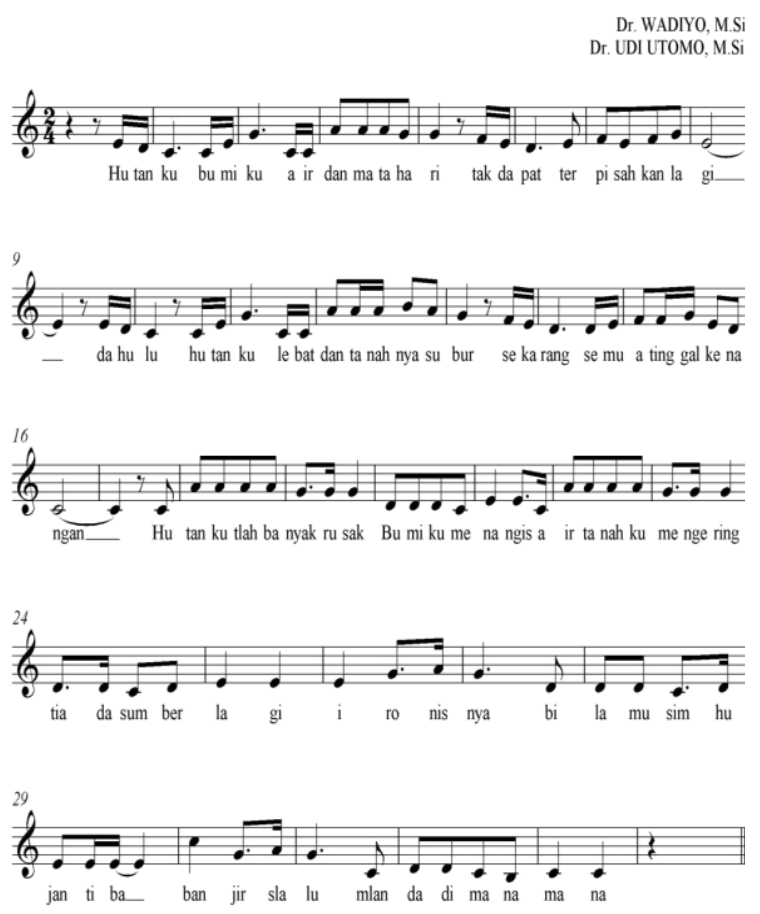

Dr. WADIY0, M.Si Dr. Udi Utomo, M.Si

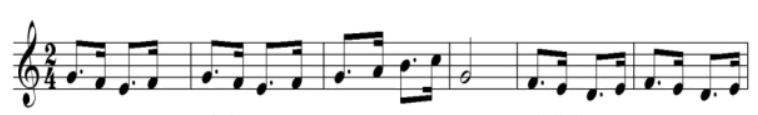

Hampa ran sa wah hutan gu nung la ut lu as Mi lik bang sa ki ta bang sa

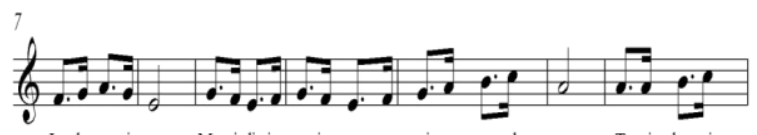

In do ne si a Ma ri di ja ga ja ngan sam pai me ru sak nya Tun ju kan si

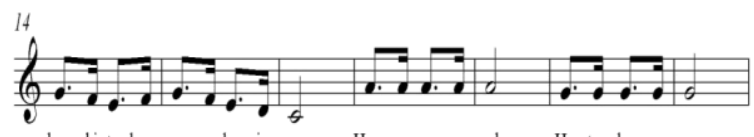

kap ki ta bang sa a dap ja ya Ham pa ran sa wah Hu tan dan gu nung

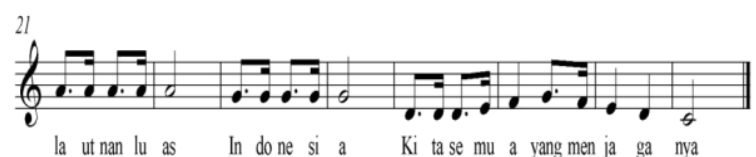

SIMPULAN

Berdasar hasil pengabdian yang telah dilaksanakan oleh tim pengabdi maka dapat disampaikan simpulan berikut ini.

1. Peserta pengabdian terlihat sangat antosias mengikuti jalannya pengabdian kepada masyarakat ini karena materinya berkait dengan tema pembelajaran yang di dalamnya menyangkut pembuatan lagu untuk memasukkan materi ajar berdasar tema pembelajaran yang dituangkan dalam kurikulum yang berlaku saat ini. Keantosiasan ini berangkat dari para guru Sekolah Dasar yang merasa tidak memiliki lagu-lagu yang tepat untuk memasukkan materi ajar sesuai dengan tema ajar yang harus dijalankan dalam sehari-hari. 
2. Pembuatan lagu menggunakan tema pembelajaran oleh para peserta pengabdian dirasa menjadi sangat penting namun demikian para peserta pengabdian masih harus belajar lebih banyak agar dapat melagukan isi dari materi ajar yang diambil dari tema pembelajaran. Semua dapat melakukan pembuatan lagu berdasar tema pembelajaran namun demikian alur lagunya belum stabil dan atau masih berubah-ubah serta belum sekali dinyanyikan langsung diterima anak.

\section{DAFTAR PUSTAKA}

Djohan. 2003. Psikologi Musik. Yogyakarta: Buku Baik. Jamalus dan Mahmud, AT.1981. Musik dan Pengembangan Buku SPG. Jakarta: Titik Terang.

Van de Carr, F Rene dan Lehrer March. 2004. Cara Baru Mendidik Anak Sejak Dalam Kandungan. Bandung: Kaifa.

Wadiyo, Joko Wiyoso, dan Slamet Haryono. 1998. Profil Guru SD Negeri Se Kodya Semarang Dalam Pengajaran Seni Musik. Semarang: Lemlit IKIP Semarang.

Wadiyo, Joko Wiyoso, dan Slamet Haryono. 2009. Model Pemberdayaan Masyarakat untuk Menciptakan Lagulagu Bertemakan Pendidikan melalui Pengembangan Musik Industri Lokal. Semarang: LP2M Universitas Negeri Semarang.

Wadiyo, Joko Wiyoso, dan Slamet Haryono. 2010. Model Pengembangan Materi Ajar Seni Musik \& Tari di Taman Kanak-kanak.Semarang: LP2M Universitas Negeri Semarang.

Wadiyo, Joko Wiyoso, dan Slamet Haryono. 2011. Lagu Anak-anak: Kajian tentang Metode Penciptaannya. Semarang: LP2M Universitas Negeri Semarang.
Wadiyo, Joko Wiyoso, dan Slamet Haryono. 2012. Industri Lagu Anak: Pemberdayaan Masyarakat untuk Menciptakan Lagu Anak-anak sebagai Upaya Pemenuhan Kebutuhan akan Lagu Anak-anak yang Bertemakan Pendidikan. Semarang: LP2M Universitas Negeri Semarang.

Wadiyo, Joko Wiyoso, dan Slamet Haryono. 2013. Industri Lagu Anak: Pemberdayaan Masyarakat untuk Menciptakan Lagu Anak-anak sebagai Upaya Pemenuhan Kebutuhan akan Lagu Anak-anak yang Bertemakan Pendidikan (Tahap II). Semarang: LP2M Universitas Negeri Semarang.

Wadiyo, dkk. 2015. Model Lagu Sebagai Alat Penyampaian Pesan Pendidikan untuk Anak-anak Prasekolah (TAHAP 1). Semarang: Universitas Negeri Semarang.

Wadiyo. 2015. Model Lagu Sebagai Alat Penyampaian Pesan Pendidikan untuk Anak-anak Prasekolah (TAHAP I1). Semarang: Universitas Negeri Semarang. 